\title{
Development of an Implementation Framework for Integrated Management System Based on the Philosophy of Total Quality Management
}

\author{
Subrata Talapatra', Md. Kutub Uddin'2, Md. Habibur Rahman'1 \\ ${ }^{1}$ Department of Industrial Engineering and Management (IEM), Khulna University of Engineering \& Technology (KUET), \\ Khulna, Bangladesh \\ ${ }^{2}$ Department of Mechanical Engineering (ME), Khulna University of Engineering \& Technology (KUET), Khulna, Bangladesh \\ Email: habibur091@gmail.com
}

How to cite this paper: Talapatra, S., Uddin, M.K. and Rahman, M.H. (2018) Development of an Implementation Framework for Integrated Management System Based on the Philosophy of Total Quality Management. American Journal of Industrial and Business Management, 8, 1507-1516. https://doi.org/10.4236/ajibm.2018.86101

Received: April 24, 2018

Accepted: June 12, 2018

Published: June 15, 2018

Copyright $\odot 2018$ by authors and Scientific Research Publishing Inc. This work is licensed under the Creative Commons Attribution International License (CC BY 4.0).

http://creativecommons.org/licenses/by/4.0/ (c) (i) Open Access

\begin{abstract}
The focus of this paper is to develop a framework for implementation of integrate management systems (ISO 9001, ISO 14001, OHSAS 180001 and SA 8000). At present, these management systems are used individually in several industrial organizations. Dealing with these separate management systems and ensuring their alignment with business goal are the two big issues. Increased compatibility between these standards has paved the road for integration. With the co-ordination of holistic approach like TQM, it can easily embed the existing quality, health \& safety, social responsibility and environmental processes in the culture of continuing improvement. Several researches have been conducted to understand the different aspects of integration. But, no suitable aspect of integration has been developed yet. The main finding of this paper concludes that, integration on the basis of philosophical compatibility between TQM and other standards can create a generic approach for implementation. Furthermore, this aspect of integration will also give administrative benefits related to implementation and maintenance of the systems.
\end{abstract}

\section{Keywords}

Integrated Management, Environment, TQM, Safety, Reliability

\section{Introduction}

This research gives an overview of development of a model for integrated management system (IMS). This management system will include the whole product 
chain and all the stakeholders. A current trend research is continuously looking for better aspect of integration of different management system such as ISO 9001, ISO 14001, and OHSAS 18001 [1]. During the last decade, ISO standards revision has paved the road towards more compatible management standards with cross reference of system elements [2]. However, integration based on compatible criteria could be an ordinary step towards IMS. Projecting the various disciplines in a single management system on the basis of their cross-functional linkage is a prerequisite for better integration [3]. In order to realize the internal co-ordination and right trade off among the various management systems [4], it is essential to create a culture of learning, stakeholder participation and continuous improvement of process performance [4] [5].

To ensure satisfaction of customer's various demands, the organization has to practice some parallel compliance standards in which they operate. Several studies have identified some common compliance standards that are practicing in Readymade garment (RMG) that is an important sector in Bangladesh [6]. They are ISO 9001 (quality), ISO 14001 (environment), OHSAS (health \& safety) and SA 8001 (social compliance). Dealing with separate management systems at a time covering quality, environment, safety \& health, and social accountability is really a difficult task. Again the alignment of the objectives of these management systems with organizational goal is always hampered [7]. In this situation, integration of different management system is a burning issue. The present paper has taken right step to address the issue. This paper has correctly identified that, the compatibility of cross references of difficult management systems cannot ensure the effective way of integration alone. A wider platform is essential for internal coordination of philosophical compatibility among the various management systems [8]. The main objective of this paper is to develop a framework for implementation of integrated management systems to meet up the demands of all stakeholders in an organization.

This article is organized into six sections for the completion of its objectives and the organization is literature review in Section 2, methodology of integration in Section 3, reasons for integration in Section 4, comparing the scope of integrations of different management standards in Section 5 and proposing a framework for integrated management system implementation in Section 6.

\section{Literature Review}

ISO 9001, ISO 14001 and OHSAS 18001 have requirements for continuous improvement, but the adoption of the standards is not a guarantee that improvements will be made. A holistic approach like TQM can easily merge the existing quality, health \& safety, environmental and social responsibility processes into a single cross-functional management system. Wilkinson and Dale (2011) have correctly pointed out that an IMS should have a common concept with no significance differences in the scope of individual management system [9]. Further, they emphasize the need for strong culture, which supports the main elements of 
TQM like involvement, teamwork, training, commitment and leadership. Granerud and Rocha (2011) conducted their research in South Wales in UK suggesting a team based approach to solve a problem in IMS and include ideas and actions from all employees [10]. Jargensen et al. (2005) have mentioned that TQM has already emphasized the embedding in organizational culture and active participation of employee etc. [11].

Typically, the organization that has already a quality management system and later it integrates other management systems, it creates a problem of neglecting the other system compared to quality [12].

The level of integration that an organization decides to pursue in the design of its management system(s) will depend on both the complexity of its current management system(s) and on the motives of the organization that pursue integration [13].

Sampaio et al. (2012) expressed the concern that, in order to create positive interactions between the fields of management, a positive vision is required. Adopting a pro-active approach to problem solving provides an opportunity of better integration than just integration of systems and process aspects [14].

Issues such as the organization's structure, size, market competition and regulatory in demand have a decisive influence; when an organization decides whether to integrate or not, as well as for the level of integration [7] [8] [15] [16]. Further research needs to be performed to examine the issue more closely. In this connection, this research work wants to establish a practical example of integration of various management systems like quality, health \& safety, environmental and social responsibility that are climbing higher up the responsibility of RMG sector to satisfy all of its stakeholders (customers, employees, supplier and society). We have derived our research objectives as: 1) to find out the compatibilities among different management systems 2) to develop an implementation framework of integrated management under the philosophy of TQM.

\section{Methodology of Integration}

There are several methods of integration of different management systems. We have divided our method of integration into two steps:

Step one (partial integration): Integration based on the compatibilities among the different management standards. This will develop a common standard for quality, health \& safety, environment, and social responsibility and a universal audit system.

Step two (total integration): This model has gone beyond common procedure and involves an integration based on continuous improvement philosophy of TQM.

\section{Reason for Integration}

Nowadays buyers are very much concern about the product quality as well as safety and protection of right of workers [17] [18] [19]. Regarding this issue, several management systems have been practiced throughout the world which is 
summarized in Table 1 with the areas of applications.

RMG sectors of Bangladesh are seriously practicing compliance standards according to the buyers various demand. Although each management system is unique in terms of their management policy and objectives, the audit of these individual management systems conducted on the basis of their functional needs [20]. But duplications of effort usually happen in some common cross functional areas while practicing different management systems [21]. Therefore, there is a probability of misalignment of audit objectives from the organizational goal. Even the parallel running management system is very conservative shearing their resource and audit expertise [22].

Therefore, to overcome the above major limitations the necessity of integrated management system is obvious.

\section{Comparing the Scope of Integrations of Different Management Standards}

An integrated management system is easier to operate and manage. But a common framework is necessary for integrating two or more management standards [4] [23]. To develop a common framework is really complex issue. In our study, firstly common requirements of various management systems are identified. Secondly, common requirements are brought into single management system. We have referred this integration as partial integration. ISO 9001, ISO 14001, OHSAS 18001 and SA 8000 are compatible with each other. They can be easily integrated on the basis their common requirements. For an example, there are seventeen common elements in the management standard that are mentioned previously in this paragraph. A symmetric representation of integration of different management system on the basis of their common criteria is clearly presented in Figure 1.

In real practice no organizational activities is unique in nature, rather it is interlinked with other activities [24]. Therefore joining the individual management system will not solve the actual purpose of integration [25]. It can only fulfil one demand of integration that is higher degree of constancy among the different management standard.

Integration on the basis of cross functional linkage among the various disciplines could be a better framework for integration. We have referred this integration as total integration.

Table 1. Several management systems used throughout the world.

\begin{tabular}{cc}
\hline Field & Compliance standards used \\
\hline Quality management & ISO9001, ISO1471, ISO28001, HOKLAS, TS 16949, ISO \\
Environmental management & 100002, BABT \\
Social accountability management & ISO 14001, COC/FCS, IECQ,WEEE, ROHS \\
Organizational health \& safety & SA 8000, ICTI, AA1000, WRAP, CSR, ETI
\end{tabular}




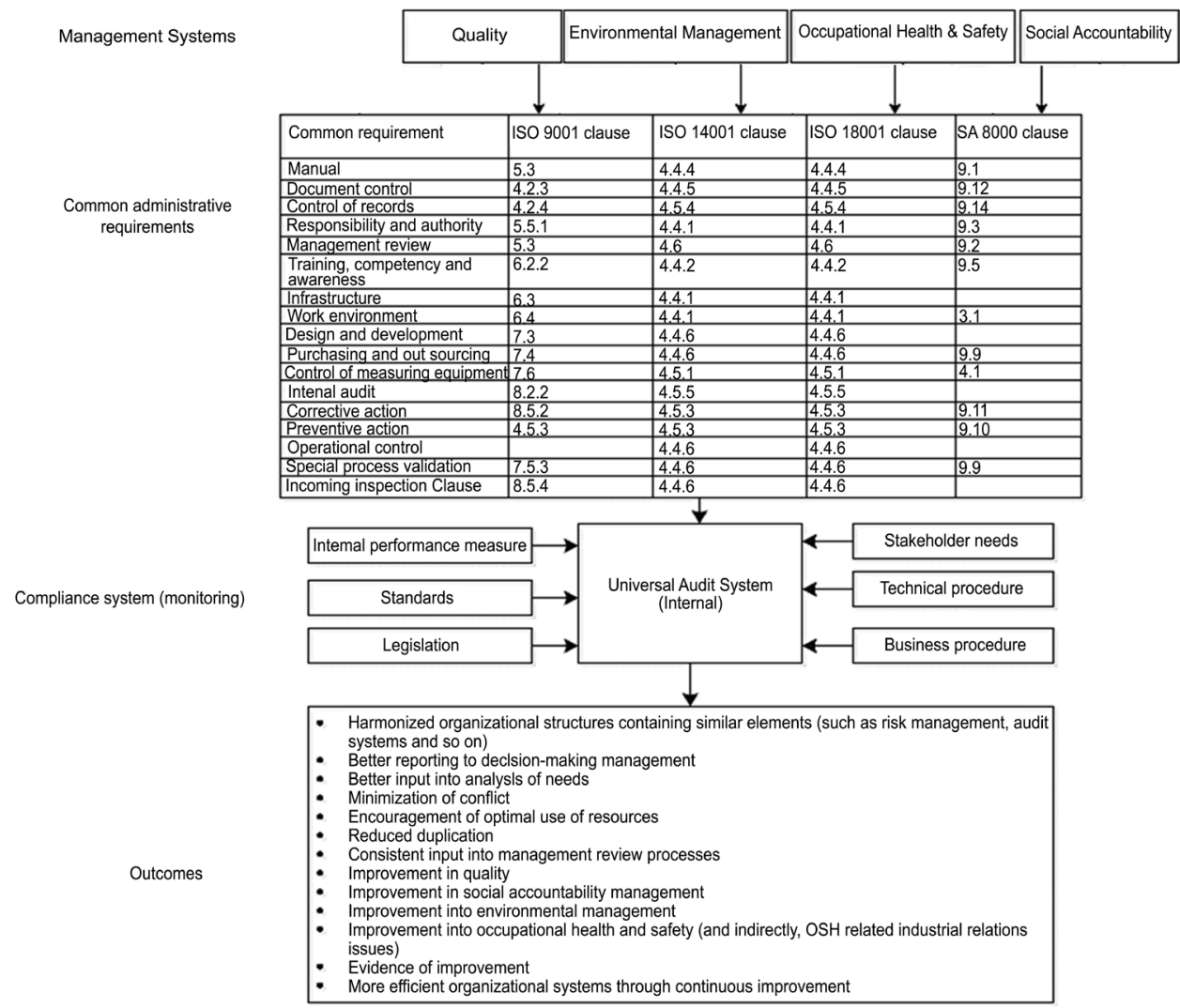

Figure 1. Framework for an integrated management system.

Most of the time integration does not ensure the degree of consistency among the different functional audit [26]. As a result the integration of different management standard does not act properly in an organization due to lack of single comprehensive universal audit system [17] [21].

In our research framework, we have projected multidisciplinary functions in a single management system and tried to integrate them under the holistic philosophy of TQM. But our cross functional integration will definitely make an audit system truly universal because it can assess the performance of various functions of an organization.

TQM looks after the continuous improvement of overall system of an organization [27] [28]. Therefore, all the separate management system that is running simultaneously can be viewed as a subset of TQM. On the others word, Holistic approach of TQM has given an opportunity to integrate all operational process in the area of quality, occupational health and safety, environmental and social accountability. Relationship between TQM and others management systems is described in Table 2.

An understanding from the above aspects has cleaned that, the current study has successfully investigate the common factors that are equally important for meeting the requirements of different management systems as well as the philosophy of TQM practices. Moreover, this six common factors will potentially serve as a base line and become a sources of general guideline in integrating the 
Table 2. Some common Philosophy shared by TQM and other compliance standards.

\begin{tabular}{|c|c|}
\hline TQM Philosophy & Common Compliance Practices \\
\hline Continual Improvement & $\begin{array}{l}\text { To achieve organizational excellence, a continuous improvement is required not only in quality but also in } \\
\text { others aspects (occupational health and safety, environmental and social accountability) of the organization } \\
\text { [29]. When everybody in an organization will hunt for better working procedures an improvement habit will } \\
\text { be established in the company. Sometimes new improvement will open some new areas of further } \\
\text { improvement. A continuous improvement culture will continue throughout the organization. This culture will } \\
\text { also help the company to establish TQM philosophy in the organization. }\end{array}$ \\
\hline Employee Participations & $\begin{array}{l}\text { Employee participations have a great influence on TQM practices. A friendly working environment will ensure } \\
\text { more employee participations in work [30]. This will increase the team spirit as well as moral of the employee. } \\
\text { A friendly working environment depends upon some good practices. They are regular payment, job security, } \\
\text { formal recruitment, no wages penalties and discriminations. This is also the requirements of social } \\
\text { accountability. }\end{array}$ \\
\hline $\begin{array}{l}\text { Delegation of Authority and } \\
\text { Responsibility }\end{array}$ & $\begin{array}{l}\text { TQM initiatives require a top management support to achieve the organizational goal. If the top management } \\
\text { to assign authority and responsibility among the employee, everybody will be wait for other people to do their } \\
\text { jobs [31]. As a result the organization will fails to achieve its goal. } \\
\text { Although the goal of the different management systems are different in nature. But it is essential to assign } \\
\text { authority and responsibility among the employee to achieve these goals. }\end{array}$ \\
\hline Employee Training & $\begin{array}{l}\text { Training is very much essential to identify and implement several improvement initiatives undertaken by } \\
\text { various disciplines [32]. Training will increase the capability and knowledge of the employee how to perform } \\
\text { job more efficiently. This will bring greater degree of commitment, motivation, (Therefore, employee } \\
\text { development) among the employee as well as higher level of productivity. An important exception of TQM } \\
\text { can be fulfilled by training. }\end{array}$ \\
\hline Leadership & $\begin{array}{l}\text { A wide variety of activities in different management systems are directly linked with firm performance. The } \\
\text { role of the leadership is to ensure well matching of existing activities with the objectives of each management } \\
\text { system [33]. This will motive the employees towards the ultimate goal of the organizations. Therefore, a good } \\
\text { leadership can enhance the productive and constructive approach to the management system in pursuit of } \\
\text { TQM implementation. }\end{array}$ \\
\hline Employee Empowerment & $\begin{array}{l}\text { In order to establish an environment of quality excellence in the organizations, employee participations are } \\
\text { obvious. Employee empowerment is a pre-requisite initiative to increase the participations of employee in } \\
\text { their works [34]. Therefore, employee empowerment is the ultimate measure of firm performance, which } \\
\text { actually determines the success and failure of TQM implementation. }\end{array}$ \\
\hline
\end{tabular}

several management stands. On others words, combining all these management system (quality, occupational health and safety, environmental and social accountability) in order to implement a single integrated management system (IMS) is considered to meet the compliance requirements in these areas.

\section{A Framework for Integrated Management System Implementation}

The philosophy of TQM has been much reflected in the quality, occupational health and safety, environmental and social accountability, management system. Therefore, an integrated management system emphasis on the continuous improvement of culture, which support the four main elements of TQM implementation like planning, executions, review and modifications. In other words, the framework of implementation of integrated management system is a generic process. An integrated management system will act properly only when the phi- 
losophy of TQM will correctly integrate the objectives of different management systems [18] [35]. Figure 2 gives the interpretation of how integration of different management system can be accomplished by TQM implementations. The flow of steps is shown by numbers. The inter connection between the steps are elaborated by line arrow. When the staring committee is formed for TQM implementation, the committee will incorporate the integrated management system in their action plan. The staring committee will regularly seek feedback from the cross functional teams about the obstacle to implement the integrated management system and make necessary corrective action as shown in the diagram. Activities of to executive, staring committee, and operational team are shown in different levels of hierarchy in the framework.

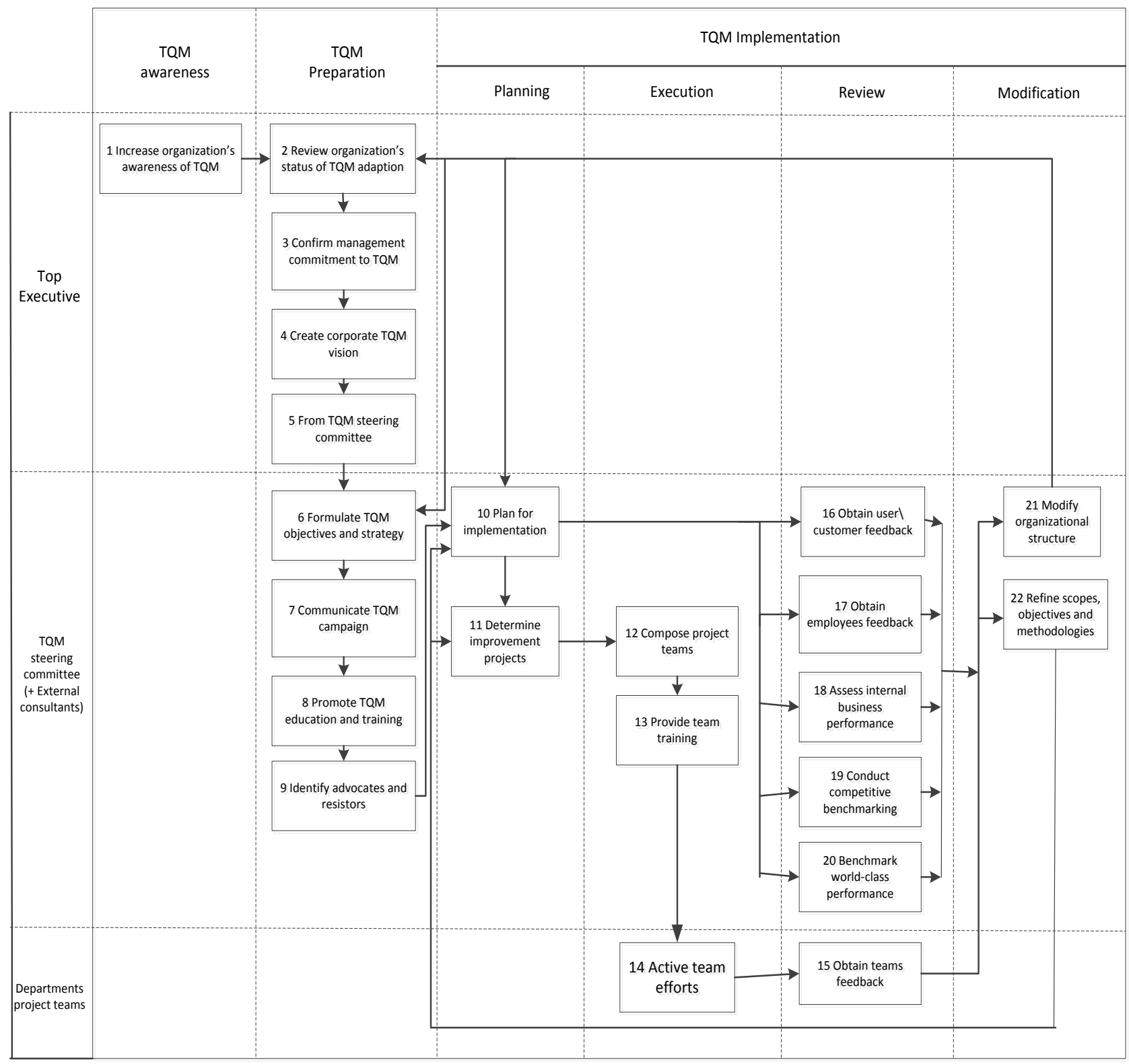

Figure 2. Various stages of TQM implementation. 


\section{Conclusion}

Globalization has changed the world significantly in the last decade. Now the organizations are permanently under a progressive pressure associated with the diversified requirement of stakeholders. The real need of integration of different management systems is a fact in this context. The requirement of continuous improvement is discussed in equivalent clauses of different management systems. For this reason, the developed model of integration has incorporated the continuous improvement philosophy of TQM as a baseline for integration. Similarities of the several elements of ISO 9001, ISO 14001, OHSAS 18001 and SA 8001 have drawn the special attention to start the activities of integration and create a framework of partial integration. Finally, the total integration is made by cross-functional competence among them. Our concept of information has added values not only for the organization, as well as for the whole range of stakeholders. This model will also eliminate the conflicts between individual management systems that are operating simultaneously in the organization. This integration will add value for the business through the elimination of several types of wastes. This model is very simple to implement and can be considered to be adopted by several other organizations in different areas of activity of different dimensions and market positions. The main limitations of this study are that dimensions of integration have not been tested empirically. Future studies should focus on the identification of items for each of these dimensions in order to construct reliable, valid measure for integrated management system.

\section{References}

[1] Abad, J., Dalmau, I. and Vilajosana, J. (2014) Taxonomic Proposal for Integration Levels of Management Systems Based on Empirical Evidence and Derived Corporate Benefits. Journal of Cleaner Production, 78, 164-173. https://doi.org/10.1016/j.jclepro.2014.04.084

[2] Bernardo, M., Casadesus, M., Karapetrovic, S. and Heras, I. (2010) An Empirical Study on the Integration of Management System Audits. Journal of Cleaner Production, 18, 486-495. https://doi.org/10.1016/j.jclepro.2009.12.001

[3] Bernardo, M., Casadesus, M., Karapetrovic, S. and Heras, I. (2011) Relationships between the Integration of Audits and Management Systems: An Empirical Study. The TQM Journal, 23, 659-672. https://doi.org/10.1108/17542731111175266

[4] Bernardo, M., Casadesus, M., Karapetrovic, S. and Heras, I. (2012) Integration of Standardized Management Systems: Does the Implementation Order Matter? International Journal of Operations \& Production Management, 32, 291-307. https://doi.org/10.1108/01443571211212583

[5] Holm, T., Vuorisalo, T. and Sammalisto, K. (2015) Integrated Management Systems for Enhancing Education for Sustainable Development in Universities: A Memetic Approach. Journal of cleaner production, 106, 155-163. https://doi.org/10.1016/j.jclepro.2014.03.048

[6] ISO (2013) The ISO Survey of Certifications. International Organisation for Standardization, Geneva, Switzerland.

[7] Marimon, F., Llach, J. and Bernardo, M. (2011) Comparative Analysis of Diffusion 
of the ISO 14001 Standard by Sector of Activity. Journal of Cleaner Production, 19, 1734-1744. https://doi.org/10.1016/j.jclepro.2011.06.003

[8] Mokhtar, M.Z. and Muda, M.S. (2012) Comparative Study on Performance Measures and Attributes between ISO and Non-ISO Certification Companies. International Journal of Business and Management, 7, 185-193.

https://doi.org/10.5539/ijbm.v7n3p185

[9] Wilkinson, G. and Dale, B.G. (2001) Integrated Management Systems: A Model Based on a Total Quality Approach. Managing Service Quality: An International Journal, 11, 318-330. https://doi.org/10.1108/09604520110404040

[10] Granerud, R.L. and Rocha, R.S. (2011) Organisational Learning and Continuous Improvement of Health and Safety in Certified Manufacturers. Safety Science, 49, 1030-1039. https://doi.org/10.1016/j.ssci.2011.01.009

[11] Jørgensen, T.H., Remmen, A. and Mellado, M.D. (2006) Integrated Management Systems-Three Different Levels of Integration. Journal of Cleaner Production, 14, 713-722. https://doi.org/10.1016/j.jclepro.2005.04.005

[12] Moneva, J.M. and Ortas, E. (2010) Corporate Environmental and Financial Performance: A Multivariate Approach. Industrial Management \& Data Systems, 110, 193-210. https://doi.org/10.1108/02635571011020304

[13] Mellat Parast, M., Adams, S.G. and Jones, E.C. (2011) Improving Operational and Business Performance in the Petroleum Industry through Quality Management. International Journal of Quality \& Reliability Management, 28, 426-450. https://doi.org/10.1108/02656711111121825

[14] Sampaio, P., Saraiva, P. and Domingues, P. (2012) Management Systems: Integration or Addition? International Journal of Quality \& Reliability Management, 29, 402-424. https://doi.org/10.1108/02656711211224857

[15] Santos, G., Mendes, F. and Barbosa, J. (2011) Certification and Integration of Management Systems: The Experience of Portuguese Small and Medium Enterprises. Journal of Cleaner Production, 19, 1965-1974. https://doi.org/10.1016/j.jclepro.2011.06.017

[16] Simon, A. and Douglas, A. (2013) Integrating Management Systems: Does the Location Matter? International Journal of Quality \& Reliability Management, 30, 675-689. https://doi.org/10.1108/02656711311325629

[17] Simon, A., Bernardo, M., Karapetrovic, S. and Casadesús, M. (2011) Integration of Standardized Environmental and Quality Management Systems Audits. Journal of Cleaner Production, 19, 2057-2065. https://doi.org/10.1016/j.jclepro.2011.06.028

[18] Talapatra, S. and Uddin, M.K. (2017).Some Obstacles that Affect the TQM Implementation in Bangladeshi RMG Sector: An Empirical Study. Proceedings of the 8th International Conference on Industrial Engineering and Operations Management, Bandung, 6-8 March 2018, 1290-1302.

[19] Talapatra, S. and Rahman, M.H. (2016) Safety Awareness and Worker's Health Hazards in the Garments Sector of Bangladesh. European Journal of Advances in Engineering and Technology, 3, 44-49.

[20] Simon, A., Karapetrovic, S. and Casadesús, M. (2012) Difficulties and Benefits of Integrated Management Systems. Industrial Management \& Data Systems, 112, 828-846. https://doi.org/10.1108/02635571211232406

[21] Simon, A., Yaya, L.H.P., Karapetrovic, S. and Casadesús, M. (2014) An Empirical Analysis of the Integration of Internal and External Management System Audits. Journal of Cleaner Production, 66, 499-506. 
https://doi.org/10.1016/j.jclepro.2013.11.020

[22] José Tarí, J. and Molina-Azorín, J.F. (2010) Integration of Quality Management and Environmental Management Systems: Similarities and the Role of the EFQM Model. The TQM Journal, 22, 687-701. https://doi.org/10.1108/17542731011085348

[23] Tarí, J.J., Claver-Cortés, E., Pereira-Moliner, J. and Molina-Azorín, J.F. (2010) Levels of Quality and Environmental Management in the Hotel Industry: Their Joint Influence on Firm Performance. International Journal of Hospitality Management, 29, 500-510. https://doi.org/10.1016/j.ijhm.2009.10.029

[24] Tarí, J.J., Molina-Azorín, J.F. and Heras, I. (2012) Benefits of the ISO 9001 and ISO 14001 Standards: A Literature Review. Journal of Industrial Engineering and Management, 5, 297. http://dx.doi.org/10.3926/jiem.488

[25] Zeng, S.X., Xie, X.M., Tam, C.M. and Shen, L.Y. (2011) An Empirical Examination of Benefits from Implementing Integrated Management Systems (IMS). Total Quality Management, 22, 173-186. https://doi.org/10.1080/14783363.2010.530797

[26] Ferreira Rebelo, M., Santos, G. and Silva, R. (2014) A Generic Model for Integration of Quality, Environment and Safety Management Systems. The TQM Journal, 26, 143-159. https://doi.org/10.1108/TQM-08-2012-0055

[27] Asif, M., Searcy, C., Zutshi, A. and Fisscher, O.A. (2013) An Integrated Management Systems Approach to Corporate Social Responsibility. Journal of Cleaner Production, 56, 7-17. https://doi.org/10.1016/j.jclepro.2011.10.034

[28] Khanna, H.K., Laroiya, S.C. and Sharma, D.D. (2010) Integrated Management Systems in Indian Manufacturing Organizations: Some Key Findings from an Empirical Study. The TQM Journal, 22, 670-686.

https://doi.org/10.1108/17542731011085339

[29] Leopoulos, V., Voulgaridou, D., Bellos, E. and Kirytopoulos, K. (2010) Integrated Management Systems: Moving from Function to Organisation/Decision View. The TQM Journal, 22, 594-628. https://doi.org/10.1108/17542731011085302

[30] Zorpas, A. (2010) Environmental Management Systems as Sustainable Tools in the Way of Life for the SMEs and VSMEs. Bioresource Technology, 101, 1544-1557. https://doi.org/10.1016/j.biortech.2009.10.022

[31] Abad, J., Lafuente, E. and Vilajosana, J. (2013) An Assessment of the OHSAS 18001 Certification Process: Objective Drivers and Consequences on Safety Performance and Labour Productivity. Safety Science, 60, 47-56.

https://doi.org/10.1016/j.ssci.2013.06.011

[32] Blewett, V. and O'Keeffe, V. (2011) Weighing the Pig Never Made It Heavier: Auditing OHS, Social Auditing as Verification of Process in Australia. Safety Science, 49, 1014-1021. https://doi.org/10.1016/j.ssci.2010.12.010

[33] De Oliveira, O.J. (2013) Guidelines for the Integration of Certifiable Management Systems in Industrial Companies. Journal of Cleaner Production, 57, 124-133. https://doi.org/10.1016/j.jclepro.2013.06.037

[34] Garengo, P. and Biazzo, S. (2013) From ISO Quality Standards to an Integrated Management System: An Implementation Process in SME. Total Quality Management \& Business Excellence, 24, 310-335. https://doi.org/10.1080/14783363.2012.704282

[35] Talapatra, S. and Uddin, M.K. (2017) Understanding the Difficulties of Implementing TQM in Garments Sector: A Case Study of Some RMG Industries in Bangladesh. International Conference on Mechanical, Industrial and Materials Engineering 2017 (ICMIME2017), Rajshahi, 25-26 December 2017, 28-30. 